\title{
D/L arabinitol Ratio as an Indicator of a Healthy Lifestyle. A preliminary Study
}

\author{
Joanna Kałużna-Czaplińska, Wioletta Grys, Tomasz Jędrzejczyk \\ and Jacek Rynkowski \\ Institute of General and Ecological Chemistry, Lodz University of Technology, Poland \\ joanna.kaluzna-czaplinska@p.lodz.pl \\ Institute of General and Ecological Chemistry, Lodz University of Technology, Poland \\ wioletta.grys@interia.pl \\ Institute of General Food Chemistry, Lodz University of Technology, Poland \\ tomasz.jedrzejczyk@p.lodz.pl \\ Institute of General and Ecological Chemistry, Lodz University of Technology, Poland \\ jacek.rynkowski@p.lodz.pl
}

\section{ABSTRACT}

D-arabinitol, as opposed to the L-arabinitol, is produced by fungi of the genus Candida. The increased D/L-arabinitol ratio in body fluids is a recognized biomarker of systemic fungal infection. The factors which increase the risk of candidiasis include: sugar and confectionery, sweetened sodas, alcohol, beer, coffee, black tea, red meat, refined flour products, tobacco and salt. Often, vitamin deficiencies are caused by candidiasis of the colon. The D/L ratios in urine were determined by gas chromatography with electron capture detection (GC-ECD). For 21 examined students a questionnaire survey related to their healthy lifestyle was conducted. The lower $\mathrm{D} / \mathrm{L}$ ratio in the urine of students declaring regular intake of vitamin supplements and daily consumption of fruit and/or vegetables to improve their immunity against diseases was observed. The $\mathrm{D} / \mathrm{L}$ ratio may be considered a potential indicator of a healthy lifestyle, especially in the case of young people.

\section{Indexing terms/Keywords}

D/L-arabinitol; urine; nutrition; lifestyle

\section{Academic Discipline And Sub-Disciplines}

chemistry

\section{SUBJECT CLASSIFICATION}

analytical chemistry

\section{TYPE (METHOD/APPROACH)}

experimental study

\section{Council for Innovative Research}

Peer Review Research Publishing System

Journal: Journal of Advances in Chemistry

\author{
Vol. 4, No. 2 \\ editor@cirworld.com \\ www.cirworld.com, member.cirworld.com
}




\section{INTRODUCTION}

Human health and related life expectancy depend on several factors: the environment, human biology, medicine and lifestyle [1,2]. Lifestyle is closely related to human nutrition and the use of various stimulants such as coffee, nicotine, alcohol. The study of lifestyles relies heavily on the study of health behaviors. According to literature [3,4] many diseases, such as atherosclerosis, obesity, and a neurological disorder, result from improper nutrition metabolism. One of the primary goals of health promotion is to popularize the so-called healthy lifestyle. It involves actions which maintain and improve people's health and prevent diseases. A healthy diet consists in avoiding alcohol, smoking, stress and taking regular physical exercises. It should also comprise an individualized diet [5]. For the proper functioning of the body, right amounts and proportions of proteins, fats, carbohydrates, vitamins and minerals are necessary. Eating too much of carbohydrates, i.e. refined sugar and starch products and a frequent intake of antibiotics can cause disturbances in the human body homeostasis. As a consequence, it can increase the risk of candidiasis. The factors which increase the risk of candidiasis include: sugar and confectionery, sweetened sodas, alcohol, beer, coffee, black tea, red meat, refined flour products, tobacco and salt $[6,7]$. Often, vitamin deficiencies are caused by candidiasis of the colon. The colon friendly bacteria produce from the fiber all vitamins except for vitamin $\mathrm{C}$. In the case where the reduction of these friendly bacteria and the excessive amount of Candida yeast occur, the production of these vitamins is disturbed, which results in the impaired functioning of all the metabolic processes of the body. As a result, it leads to the dysfunction of the immune system and the associated lack of resistance to viral and bacterial infections. D-arabinitol, as opposed to the L-arabinitol a normal human metabolite- is produced by fungi of the genus Candida. The increased D/L-arabinitol ratio in body fluids is a recognized biomarker of systemic fungal infection $[8,9]$. In this work, for the first time the of D/L-arabinitol ratio levels in the urine of healthy adults were related to some elements of a healthy lifestyle. The main aim of this study was to determine the urinary D/L-arabinitol ratio in a group of students who were or were not supplemented with vitamins and who showed different nutrition habits concerning the consumption of fruit and vegetables. Another aim was to evaluate the usefulness of the D/L-arabinitol ratio as a potential indicator of a healthy lifestyle.

\section{MATERIAL AND METHODS}

\subsection{Participants}

$\mathrm{D} / \mathrm{L}$-arabinitol ratios were determined in the urine of adults. Samples of the biological material were taken from the group of 21 students, aged 19-21 from the Department of Biotechnology and Food Science at Lodz University of Technoloy (Poland). For the examined students a questionnaire survey was conducted. Students were divided into 2 subgroups: A: persons receiving vitamin supplementation and simultaneously declaring the daily consumption of fruit, vegetables and juices and $B$ : persons who are not supplemented with vitamins and declare rare consumption of fruit, vegetables and juices. The study was approved by the local ethics committee.

\subsection{Analytical method}

In order to determine the urinary $\mathrm{D} / \mathrm{L}$ ratio, a method of gas chromatography with electron capture detection (GCECD) was applied. A gas chromatograph-electron capture detector (Agilent Technology) with the autosampler was used. The fused silica column coated with $\beta$-cyclodextrin layer ( $\beta$ dex 120 Supelco, $30 \mathrm{~m}$ length, $0.25 \mathrm{~mm}$ diameter and $0.25 \mu \mathrm{m}$ film thickness) was applied in order to separate the enantiomers.

\subsection{Indicators of a healthy lifestyle}

The survey which was carried out in 2 subgroups of students concerned the indicators of a healthy lifestyle such as: vitamin supplementation and simultaneous daily consumption of fruit, vegetables and juices. For both groups the consumption of 6 highly acid-forming products, i.e.: sweetmeats, coffee, fizzes drinks, red meat and drinking alcohol, cigarette smoking was compared. The frequency of their consumption was assessed in the scale $0-4$, where: $0-$ never, 1 - rarer than once a month, 2 - at least once a month, 3 - at least once a week, 4 - daily.

\subsection{Statistical analysis}

Data were statistically evaluated using statistical analysis package (StatSoft, Polska STATISTICA, version 9.0.). The Shapiro-Wilk test was used to check a normal distribution of the results. The t-Student test was used to compare urinary $\mathrm{D} / \mathrm{L}-$ arabinitol. Differences were considered statistically significant at $\mathrm{p}<0.05$.

\section{RESULTS}

Gas chromatography with the electron capture detection method was used for the analysis and the monitoring of $\mathrm{D} / \mathrm{L}$-arabinitol ratios in urine samples collected from 21 students (8 males and 13 females). The applied method was described in detail in our earlier paper [10]. The results of the $D / L-$ arabinitol ratio are shown in Table 1 . D/L ratios for males and females were $1.67 \pm 0.49$ (mean \pm SD) and $1.67 \pm 0.55$ (mean \pm SD), respectively. The differences in the $\mathrm{D} / \mathrm{L}$ levels in urine in relation to the gender were not stated ( $t$-Student test probability: $p>0.05$ ). 
Table 1. Urinary D/L-arabinitol in students

$\mathrm{n}$ - number of investigated students; ${ }^{\dagger}$ The lowest value of the $\mathrm{D} / \mathrm{L}$ ratio recorded in the group.

${ }^{\ddagger}$ The highest value of the D/L ratio recorded in the group; BMI- Body mass index;

SD-standard deviation

\begin{tabular}{ll}
\hline $\mathbf{n}$ & 21 \\
\hline Age (mean \pm SD) & $19.67 \pm 0.66$ \\
\hline Gender (male/female) & $8 / 13$ \\
\hline BMI (mean \pm SD) & $22.64 \pm 3.37$ \\
\hline D/L ratio (mean \pm SD) & $1.67 \pm 0.51$ \\
\hline${ }^{\top}$ Min: D/L ratio & 0.90 \\
\hline${ }^{\mp}$ Max: D/L ratio & 3.03 \\
\hline
\end{tabular}

Figure 1 presents the results for 2 subgroups. Group A consists of students who receive vitamin supplementation and declare daily consumption of fruit, vegetables and juices. Group B represents persons who do not receive vitamin preparations and declare raref consumption of fruit, vegetables and juices. The rate of consumption of highly acid-forming products for each person as a mean from each of 6 considered factors was expressed. For group $A$ the average rate reached a value of $2.68(S D=0.63)$, for group $B: 2.37(S D=0.55)$, the $t-S t u d e n t$ test probability $p>$ 0.05 . The influence of vitamin supplementation and a simultaneous daily intake of fruit, vegetables and juices on the D/Larabinitol levels in urine was checked in 2 subgroups at similar rates of consumption of products which could also affect the $\mathrm{D} / \mathrm{L}$ ratios. The $t$-student test probability $(p<0.02)$ lower than the accepted level of 0.05 suggested that the $D / L$ ratios were statistically significantly lower in group A. Moreover, average BMI was lower in group $A$ (but $p$-value $=0.08$ was higher than the significance level).

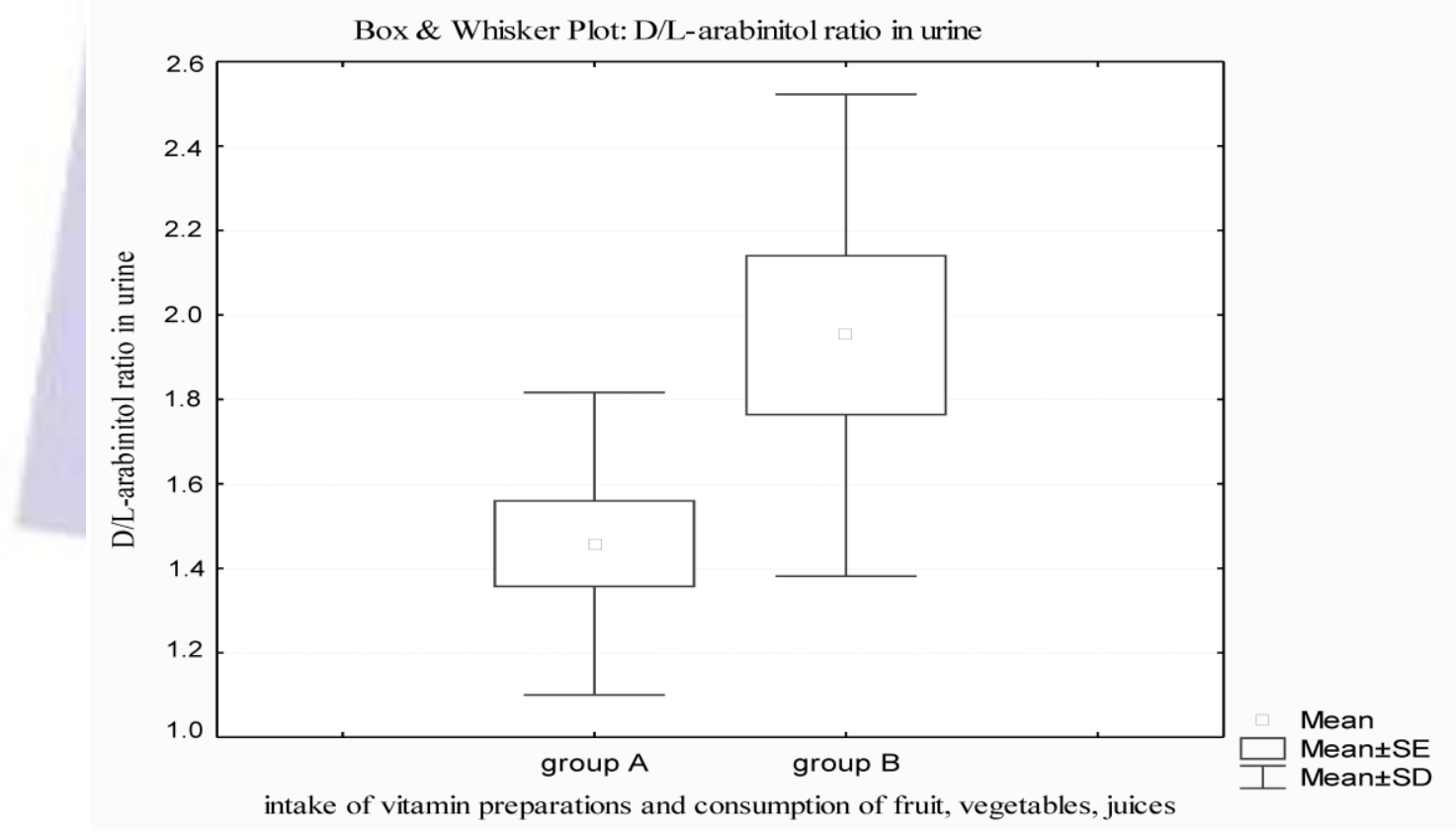

Figure 1. The $D / L$ - arabinitol ratio in urine depending on the intake of vitamin supplements and consumption of fruit, vegetables and juices:

Group A: persons who receive vitamin supplements and simultaneously declare daily consumption of fruit, vegetables and juices, $n: 12$; male/female: 4/8; the D/L ratio (mean \pm SD): $1.46 \pm 0.36$; BMI (mean \pm SD): $21.42 \pm 2.71$

Group B: persons who do not receive vitamin supplements and declare rarer consumption of fruit, vegetables and juices, n: 9; male/female: $4 / 5$; D/L ratio (mean $\pm S D$ ): $1.95 \pm 0.57$, BMI (mean $\pm S D): 24.26 \pm 3.63$ 


\section{DISCUSSION}

Hayes and Glouberman [11], Canadian epidemiologists, presented a very interesting hypothesis, which is supported by a broad list of research of factors which affect the length of life. It depends on four factors: human biology, environment, health care and lifestyle. The greatest impact on human health has a lifestyle which consists of the following elements: physical activity, ability to cope with stress, the use of stimulants (nicotine, alcohol, drug), diet and nutrition [3]. Often, we do not realize the importance and influence of a proper diet on the condition of our body. Bad eating habits can be the cause of many serious diseases and disorders. Replacing the adverse nutrients with appropriate amounts of desired substances can eliminate the causes and symptoms of many diseases [12]. One of the basic principles of rational nutrition is the regularity and frequency of consumption of food products, which provides a systematic supply of energy and essential nutrients, allowing the continuity of metabolic processes [13]. Research on nutrition and its effects on the human nutritional status indicates a negative impact of inadequate nutrition on the body and, consequently, the creation and development of many diseases, including atherosclerosis, ischemic heart disease, hypertension, obesity, type II diabetes, candidiasis [14-16].

\section{Relations between diet and body weight}

One potential outcome of unhealthy lifestyles is overweight or obesity. According to the World Health Organization (WHO), the potential cause of obesity is the consumption of foods which are high in energy density and low in nutrient density, and a lack of vitamins, minerals, and macronutrients [17]. In this paper we investigate the relation between the diet and students' body mass index (BMI = [body weight (in $\mathrm{kg}) \div$ stature (height in meters) squared]) (Table 1). We have found that the students who do not receive vitamin supplements and declare rarer consumption of fruit, vegetables and juices have BMI higher $(24.26 \pm 3.63)$ than that in group A $(21.42 \pm 2.71)$. A positive relation between the diet and body mass index is observed.

\section{Relations between gender}

There are reports $[6,18]$ where the relationship between the gender and lifestyle, such as calcium intake, smoking habits, alcohol, tea, coffee consumption, was observed. In this paper significant differences in the D/L levels in urine in relation to the gender were not stated $(p>0.05)$. The values of the $D / L$ ratios for males and females were very similar.

\section{Relations between diet and $\mathrm{D} / \mathrm{L}$ arabinitol ratio}

In literature, a positive impact of diet and the role of probiotics on the level of D/L arabinitol are discussed [1920]. Galland [22] suggests that the level of fatty acids such as 22:4 n-6 and 22:5 n-6 was significantly lower in candidiasis. The urinary $\mathrm{D} / \mathrm{L}$ arabinitol is a biomarker of several Candida species. Many results support the conclusion that the longterm antibiotic therapy leads to the increase in the $D / L$ arabinitol ratios [7-10]. Moreover, a higher ratio of $D / L$ can be associated with the consumption of acidifying products. In this report, the rates of consumption of highly acid-forming products, i.e.: sweetmeats, coffee, fizzes drinks, red meat and drinking alcohol, cigarette smoking are comparable between the groups (no statistically significant differences between groups A and B were observed, $p=0.25$ ). However, the $\mathrm{D} / \mathrm{L}$ ratios were statistically significantly lower in the group which received vitamin preparations and simultaneously declared daily consumption of fruit, vegetables and juices.

\section{CONCLUSIONS}

Lower D/L ratios in the group of respondents declaring regular daily consumption of fruit and vegetables and an intake of vitamin supplements which improve their resistance were observed. In spite of some limitations, mainly the small number of the students under study, we claim that the $D / L$ ratio may be considered a potential indicator of a healthy lifestyle, especially in the case of young people.

\section{REFERENCES}

[1] World Health Organization: World Health Report 2002: Reducing risks, promoting healthy life. Geneva, World Health Organization.Ding, W. and Marchionini, G. 1997 A Study on Video Browsing Strategies. Technical Report. University of Maryland at College Park.

[2] Djoussé, L., Driver, J.A., Gaziano, J.M. 2009. Relation between modifiable lifestyle factors and lifetime risk of heart failure. JAMA 302, 394-400.

[3] Gordon, L., Graves, N., Hawkes, A., Eakin, E. 2007. A review of the cost-effectiveness of face-to-face behavioral interventions for smoking, physical activity, diet and alcohol. Chronic. IIIn. 3, 101-129.

[4] Adams, A., Receveur, O., Mundt, M., Paradis, G., Macaulay, A.C. 2005. Healthy lifestyle indicators in children (grades 4 to 6) from the kahnawake schools diabetes prevention project. Can. J. Diab. 29, 403-409.

[5] Patten, S.B., Wang, J.L., Williams, J.W., Currie, S., Beck, C.A., Maxwell, C.J. et al. 2006. Descriptive epidemiology of major depression in Canada. Can. J. Psychiatry 51, 84-90. 
[6] Messier, L., Schmitz, N., Elisha, B., Garièpy, G., Malla, A., Lesage, A. et al. 2011. Lifestyle and care indicators in individuals with major, minor and no depression: a community-based diabetes study in Quebec. Can. J. Diab. 35, 2230.

[7] Hui, M., Cheung, S.W., Chin, M.L., Chu, K.C., Chan, R.C., Cheng, A.F. 2004. Development and application of a rapid method for invasive candidiasis by the detection of D-/L-arabinitol using gas chromatography/mass spectrometry. Diagn. Microbiol. Infect. Dis. 49, 117-123.

[8] Stradomska, T.J., Bobula-Milewska, B., Bauer, A., Mielniczuk, Z., Dabkowska, M., Syczewska, M. et al. 2005. Urinary D-arabinitol/L-arabinitol levels in infants undergoing long-term antibiotic therapy. J. Clin. Microbiol. 43, 5351-5354.

[9] Stradomska, T.J., Mielniczuk, Z. 2002. Gas chromatographic determination of D- / L-arabinitol ratio in healthy Polish children, J. Chromatogr. B 773, 175-181.

[10] Grys, W., Kałużna-Czaplińska, J., Rynkowski, J. 2011. GC-ECD method for determination of urinary D-/L-ratios in children. 4 th International Interdisciplinary Technical Conference of Young Scientists, Proceedings. Poznań : Uczelniany Samorząd Doktorantów Politechniki Poznańskiej.

[11] Hayes, M., Glouberman, S. 2004. Population health, sustainable development and policy futures. http://www.healthand everything.org/pubs/PopHealth.htm.2004.

[12] Gibson, R.S. 2005. Principles of nutritional assessment. $2^{\text {nd }}$ ed. New York: Oxford University Press.

[13] Olendzki, B.C., Ma, Y., Schneider, K.L., Merriam, P., Culver, A.L., Ockene, I.S. et al. 2009. A simple dietary message to improve dietary quality: results from a pilot investigation. Nutrition $25,736-744$.

[14] Djoussé, L., Driver, J.A., Gaziano, J.M. 2009. Relation between modifiable lifestyle factors and lifetime risk of heart failure. JAMA 302, 394-400.

[15] Eriksson, K.M., Westborg, C.J., Eliasson, M.C. 2006. A randomized trial of lifestyle intervention in primary healthcare for the modification of cardiovascular risk factors. Scand. J. Public. Health 34, 453-461.

[16] Fung, T.T., Rimm, E.B., Spiegelman, D., Rifai, N., Tofler, G.H., Willett, W.C. et al. 2001. Association between dietary patterns and plasma biomarkers of obesity and cardiovascular disease risk. Am. J. Clin. Nutr. 73, 61-67.

[17] Moustaid-Moussa, N., Costello, C.A., Greer, B.P., Spence, M., Fitzhugh, E., Muenchen, R. et al. 2012. Predictors of body mass index in female parents whose children participate in a competitive, creative, problem-solving program. Food Nutr. Res. 56, 177-187.

[18] Istiany, A. 2012. Relationship between gender, BMI, and lifestyle with bone mineral density of adolescent in urban areas. WASET 70, 351-355.

[19] Kałużna-Czaplińska, J., Błaszczyk, S. 2012. The level of arabinitol in autistic children after probiotic therapy. Nutrition 28, 124-126.

[20] Romeo, M.G., Romeo, D.M., Trovato, L., Oliveri, S., Palermo, F., Cota, F. et al. 2010. Role of probiotics in the prevention of the enteric colonization by Candida in preterm newborns: incidence of late-onset sepsis and neurological outcome. J. Perinatol. 31, 63-69.

[21] Christensson, B., Sigmunsdóttir, G., Larsson, L. 1999. D-arabinitol- a marker for invasive candidiasis. Medical Mycolog. 37, 391-396.

[22] Galland, L. 1985. Nutrition and candidiasis. J. Orthomol. Psychiatry 14, 50-60. 